\title{
Efeito do clima sobre a infecção parasitária em bezerros e presença de larvas em manejo rotativo de pasto em Santa Maria, RS, Brasil
}

\author{
Climatological effects on parasitic infection in calves and the presence of larvae \\ in a pasture rotation management in Santa Maria, RS, Brazil
}

\author{
Ivan Heck $^{1}$ Alexandre Soares Leandro ${ }^{1}$ Carla Teixeira Leite ${ }^{1}$ Jerusa Kerpel Gindri ${ }^{1}$ \\ Manuela Barros Mascarenhas de Souza ${ }^{1}$ Rômulo Depner ${ }^{1}$ Marcelo Beltrão Molento ${ }^{2}$
}

\begin{abstract}
O objetivo deste trabalho foi correlacionar os dados climáticos e parasitários através de exames laboratoriais e da pastagem. O experimento foi realizado no período de março a junho de 2004, utilizando 110 bezerros com idade média de cinco meses, em pastos com diferentes relevos. Foi avaliado o número de ovos por grama de fezes $(O P G)$, a coprocultura e o número de larvas na pastagem em intervalos de 15 dias, e dados climáticos deciduais. A coprocultura revelou a presença de $60 \%$ de parasitas do gênero Trichostrongylus spp. e 40\% de Cooperia spp. assim como Moniezia spp. e oocistos de Eimeria spp. A temperatura permitiu a sobrevivência e o desenvolvimento das larvas infectantes na pastagem durante o experimento. $O$ aumento do número de larvas na pastagem está associado ao acréscimo da precipitação após um período de seca. $O$ relevo com maior número de larvas apresentou maior concentração de massa seca de capim arroz (Echinochloa spp.). Pode-se comprovar que em condições climáticas ideais ocorreu uma rápida contaminação da pastagem com larvas infectantes quando animais naturalmente infectados foram transferidos para a área após colheita de milho.
\end{abstract}

Palavras-chave: parasitas, epidemiologia, fatores climáticos.

\section{ABSTRACT}

The objective of this work was to correlate climatic and parasitological data from laboratory and field samples. The experiment was executed from March to June of 2004, using 110 naturally infected five months old calves. The counting of eggs per gram of feces (EPG), fecal culture and the number of larva on pasture was evaluated every 15 days in relation to decidual climatic data. The EPG increased during the study. The same observation occurred with the pluviometric level. Coproculture revealed the presence of $60 \%$ of Trichostrongylus spp. and 40\% of Cooperia spp. as well as Moniezia spp. and Eimeria spp. oocists. The temperature during all the experimental periods was favorable to infecting larvae survival and development on pasture. The area with higher larvae count had the higher dry matter of "capim arroz" (Echinochloa spp.). It can be concluded that in optimal climatic conditions, there is a rapid pasture contamination with infecting larvae after the naturally contaminated animals are transferred to the area after corn harvest.

Key words: parasites, epidemiology, climatic factors.

Os parasitas gastrintestinais causam graves prejuízos à indústria pecuária, manifestando vários efeitos sobre os animais, dependendo do grau de infecção e espécie parasitária envolvida. Estas infecções são mais patogênicas em bovinos jovens com idade entre dois e 18 meses (ARMOUR, 1989). BRAGA (1986) determinou que o processo de translação, que consiste na taxa de contaminação dos animais com formas parasitárias infectantes, apresenta variação decorrente do microclima, sendo o índice

${ }^{1}$ Curso de Medicina Veterinária, Universidade Federal de Santa Maria, UFSM, Santa Maria, RS, Brasil.

'Setor de Doenças Parasitárias, UFSM. Departamento de Medicina Veterinária, Universidade Federal do Paraná, Rua dos Funcionários, 1540, 80035-050, Curitiba, PR, Brasil. E-mail: molento@ufpr.br. Autor para correspondência. 
pluviométrico o principal fator responsável pelo aumento das infecções parasitárias. No entanto, o déficit hídrico, como seu excesso, prejudica significativamente o desenvolvimento de larvas infectantes no pasto.

O objetivo deste trabalho foi correlacionar o efeito do clima sobre a infecção de parasitas gastrintestinais em bezerros naturalmente infectados e a infestação de larvas na pastagem. Neste mesmo experimento, foi avaliada a concentração de larvas infectantes após alternância de pastagem no município de Santa Maria, RS.

O experimento foi realizado na Depressão Central do Estado do Rio Grande do Sul, à altitude de 95 m, latitude de $29^{\circ} 43^{\prime}$ sul e longitude de $53^{\circ} 42^{\prime}$ oeste, no período de março a junho de 2004 . O clima, conforme a classificação de Koppen, é Cfa (subtropical úmido), com precipitação média anual de $1769 \mathrm{~mm}$, temperatura média anual de $19,2^{\circ} \mathrm{C}$, com média mínima de $9,3^{\circ} \mathrm{C}$ em junho e média máxima de $24,7^{\circ} \mathrm{C}$ em janeiro (MORENO, 1961).

Foram utilizados 110 bezerros com idade média de cinco meses e peso médio de $98 \mathrm{~kg}$ das raças Nelore, Charolês e suas cruzas recíprocas. Os animais receberam tratamento antiparasitário com abamectina (Abamectina 1\%, Jofadel) no dia-60 pré-experimento, permanecendo então com infecção natural. Os animais foram mantidos até abril em pastagem de 12ha com uma carga animal de $898 \mathrm{~kg} \mathrm{ha}^{-1}$ de peso vivo. No mês de maio, os animais foram transferidos para uma área após colheita de milho (17/ha). A área experimental apresentava topografia diferenciada: plana, leve e moderada, com composição vegetal variada. Foram colhidas amostras da pastagem para verificação do número de larvas e matéria seca (MS). Os parâmetros climáticos (índice pluviométrico, umidade relativa do ar e temperatura diária) foram obtidos junto à Estação Meteorológica do Departamento de Fitotecnia da UFSM, com amostragem decidual.

As colheitas de fezes (ampola retal) e amostras da pastagem foram realizadas a cada 15 dias. Vinte amostras de pasto por relevo foram colhidas rente ao solo, sendo $80 \%$ de perto e $20 \%$ de longe do bolo fecal. Para contagem de ovos/oocistos por grama de fezes (OPG), utilizou-se a técnica de GORDON \& WHITLOCK (1939) modificada. A contagem de larvas na pastagem foi baseada na técnica descrita por MOLENTO (2001) e a coprocultura foi realizada pelo método de Baermann. O delineamento experimental utilizado foi inteiramente casualizado, utilizando análise pelo teste " $t$ " de Student ao nível de 5\% de significância (SAS, 2001).

O exame de coprocultura revelou $60 \%$ de parasitas do gênero Trichostrongylus sp. e 40\% do gênero Cooperia sp. Foi determinada a presença de Moniezia sp. durante todo o período de avaliação. Oocistos de Eimeria spp. foram encontrados em número crescente entre os períodos de avaliação. Foi determinado um aumento significativo da infecção por Eimeria spp., Strongyloidea e Moniezia sp., entre os períodos (Tabela 1). Este aumento está associado ao aumento do número de larvas infectantes na pastagem. O aumento de OPG seguiu um comportamento similar à precipitação, com uma correlação de $0,99(\mathrm{P}=0,0645)$, que apresentou o menor nível no primeiro período, sendo este antecedido por uma seca prolongada previamente à realização deste trabalho. Estes resultados estão em concordância com ZOCOLLER et al. (1983), que descreveram a interação entre o aumento do índice pluviométrico com o alto índice de infecções de helmintos em bovinos jovens no Estado de São Paulo. Este comportamento pode ser comprovado pela equação:

$Y=433,78+21,48 I P-0,22 I P^{2}\left(C V=1,95 ; R^{2}=\right.$ $0,99 ; P=0,0645)$

Onde, IP é o índice pluviométrico.

Nos dois primeiros períodos não foram encontradas larvas na pastagem. Esse resultado pode ter ocorrido devido ao déficit pluviométrico acentuado que antecedeu o experimento. CATTO (1987) citou que bolos fecais de bovinos depositados na época da seca formam uma carapaça que inibe a migração das larvas, mas favorece a sobrevivência das mesmas, permanecendo estes positivos para larvas infectantes por um período prolongado. O início do achado das larvas foi descrito por CATTO \& FURLONG (1983), quando houve aumento da infecção no início e final da estação chuvosa, pelo fato de que nesses períodos as chuvas apresentam menor intensidade, favorecendo a liberação das larvas dos bolos fecais na pastagem.

Na terceira avaliação, ocorreu um aumento significativo de larvas no terreno com declive moderado, comparado aos valores encontrados nos terrenos com declive leve e plano. Este fato foi comprovado pela preferência dos animais em permanecer no terreno com declive moderado, que apresentou 26\% de MS de Echinochloa spp. quando comparado ao relevo leve (20\%) e plano (19\%). Isso contribuiu para uma maior concentração de fezes e, conseqüentemente, uma contaminação significativamente superior $(\mathrm{P}<0,05)$ de larvas na área com declive moderado.

A média da temperatura mais baixa $\left(16,9^{\circ} \mathrm{C}\right)$, entre os períodos, não demonstrou ser um fator determinante no comprometimento do desenvolvimento de larvas na pastagem (Tabela 1). Este fato está em concordância com PIMENTEL (1976) 
Tabela 1 - Média e desvio padrão do número de ovos de Strongyloidea, Moniezia sp. e Eimeria spp. por grama de fezes, em bezerros. Média e desvio padrão de precipitação, umidade relativa do ar (URA) e temperatura no município de Santa Maria, RS.

\begin{tabular}{lllll}
\hline & & \multicolumn{3}{c}{ Colheitas } \\
\cline { 2 - 5 } Categorias & \multicolumn{1}{c}{$01 / 04$} & $02 / 04-18 / 04$ & $19 / 04-01 / 05$ & $02 / 05-17 / 05$ \\
\hline Strongyloidea & $432,5 \pm 153,9 \mathrm{~b}$ & $925 \pm 692,5 \mathrm{a}$ & $955 \pm 740,5 \mathrm{a}$ & $955 \pm 854,6 \mathrm{a}$ \\
Moniezia spp. & $47,5 \pm 136,1 \mathrm{~b}$ & $430 \pm 774,7 \mathrm{a}$ & $145 \pm 435,8 \mathrm{ab}$ & $137,5 \pm 333,2 \mathrm{ab}$ \\
Eimeria spp. & $47,5 \pm 89,5 \mathrm{c}$ & $235 \pm 236,1 \mathrm{~b} \mathrm{c}$ & $447,5 \pm 661,4 \mathrm{~b}$ & $962,5 \pm 989,5 \mathrm{a}$ \\
Precipitação (mm) & $0,30 \pm 1,2 \mathrm{~b}$ & $34,6 \pm 102,6 \mathrm{a}$ & $53,7 \pm 6,0 \mathrm{a}$ & $127,8 \pm 60,5 \mathrm{a}$ \\
URA (\%) & $75,2 \pm 1,4 \mathrm{c}$ & $79,8 \pm 6,4 \mathrm{~b}$ & $79,96 \pm 7,7 \mathrm{~b}$ & $89 \pm 4,7 \mathrm{a}$ \\
Temperatura $\left({ }^{\circ} \mathrm{C}\right)$ & $23,3 \pm 4,0 \mathrm{~b}$ & $25 \pm 3,9 \mathrm{a}$ & $18,3 \pm 1,9 \mathrm{c}$ & $16,9 \pm 2,3 \mathrm{c}$ \\
\hline
\end{tabular}

Médias seguidas por letras diferentes na mesma linha diferem estatisticamente $(\mathrm{P}<0,05)$.

que relatou que a temperatura média ideal de desenvolvimento de larvas infectantes é de aproximadamente $17^{\circ} \mathrm{C}$, porém temperaturas entre $12 \mathrm{e}$ $37^{\circ} \mathrm{C}$ propiciam condições para sobrevivência de estádios pré-infectantes.

Após 15 dias da transferência dos animais para a área pós-colheita, foram encontradas 3.960 larvas $\mathrm{kg}^{-1} \mathrm{MS}^{-1}$. Este fato evidencia a alta contaminação de larvas após a transferência dos animais. O alto nível de infestação na pastagemo ocorreu devido à alta taxa de infecção dos animais, sendo estes restringidos de tratamento antiparasitário, alta lotação animal e fatores climáticos favoráveis.

O plantio e o acesso de animais em áreas após o cultivo de culturas estacionais pode reduzir o número de larvas infectantes na pastagem (ECHEVARRIA et al., 1993). Desta forma, os animais que estiverem nestas áreas terão um menor risco de contaminação. No entanto, esta estratégia pode ser equivocada, quando os animais são tratados com medicação antiparasitária de longa persistência, o que aumentará a pressão de seleção parasitária(SMITH et al., 1999).

O presente trabalho determinou que animais naturalmente infectados podem ser transferidos de pastagem, durante um período com oferta hídrica acima de $50 \mathrm{~mm}^{3} /$ mês, que permitirá a sobrevivência das larvas, ocorrendo rápida contaminação da pastagem. MOLENTO et al. (2004) propõem que a mudança de animais para pasto "limpo" seja feita sem que haja o tratamento antiparasitário prévio. O objetivo desta estratégia é preservar a população de larvas em refugia e a vida útil dos compostos antiparasitários. Estudos subseqüentes serão propostos para determinar, através de modelos matemáticos, variáveis como: taxa de contaminação animal, estação do ano, histórico da pastagem, categoria e a lotação animal. Podendo assim, auxiliar mais prontamente técnicos de campo na transferência de tecnologia e no desenvolvimento de programas de controle parasitários sustentáveis em longo prazo.

\section{AGRADECIMENTOS}

Os autores gostariam de fazer um agradecimento muito especial a Luis Fernado Glasenapp de Menezes pelo apoio e incansável auxílio na análise estatística e ao Setor de Bovinocultura de Corte do Departamento de Zootecnia/UFSM por ceder os animais e a área de pastagem.

\section{REFERÊNCIAS}

ARMOUR, J. The influence of host immunity on the epidemiology of trichostrongyle infections in cattle. Veterinary Parasitology, v.32, p.5-19, 1989.

BRAGA, R.M. Sobrevivência de larvas infectantes de nematódeos gastrintestinais de bovinos, sob condições naturais. Revista Brasileira de Medicina Veterinária, v.8, p.186188, 1986.

CATTO, J.B. Longevidade de larvas infectantes de nematódeos gastrintestinais de bovinos no Pantanal mato-grossense. Pesquisa Agropecuária Brasileira, v.22, p.847-854, 1987.

CATTO, J.B.; FURLONG, J. Nematodioses gastrintestinais em bezerros Zebus no Pantanal mato-grossense. Pesquisa Agropecuária Brasileira, v.18, p.1265-1271, 1983.

ECHEVARRIA, F.A.M. et al. Use of reseeded pastures as an aid in the control of gastrointestinal nematodes. Veterinary Parasitology, v.50, p.151-155, 1993.

GORDON, H.M.; WHITLOCK, H.V. A new technique for courting nematode eggs in sheep faeces. Journal of Council of Science and Industry Research in Australia, v.12, p.50-52, 1939.

MOLENTO, M.B. Técnica de contagem de larvas no pasto como ferramenta para diagnóstico parasitológico. In: SIMPÓSIO DA REDE DE HELMINTOLOGIA PARA A AMÉRICA LATINA E CARIBE,2, 2001, Buenos Aires, Argentina. Anales... Buenos Aires, 2001. CD-room. 
MOLENTO, M.B. et al. Sustainable worm management. Veterinary Record, v.155, p.95-96, 2004 b.

MOREno, J.A. Clima do Rio Grande do Sul. Porto Alegre: Secretaria da Agricultura, 1961. 41p.

PIMENTEL NETO, M. Epizootiologia da haemoncose em bezerros de gado de leite no estado do Rio de Janeiro. Pesquisa Agropecuária Brasileira, v.11, p.101-114, 1976.
SAS. Institute Inc. SAS Language reference, version 14, Cary, NC: SAS Institute, 2001. 1050p.

SMITH, G. et al. Anthelmintic resistance revisited: under-dosing, chemoprophylactic strategies, and mating probabilities. International Journal for Parasitology, v.29, p.77-91, 1999.

ZOCOLLER, M.C. et al. Infecção natural por helmintos gastrintestinais em bovinos durante os primeiros dois anos de vida, na região de Ilha Solteira, SP. Arquivo Brasileiro de Medicina Veterinária e Zootecnia, v.35, p.823-835, 1983. 